\title{
Die invloed wat Calvyn uitgeoefen het op die samestelling van die eerste kerkordes van die Franse, Skotse en Nederlandse Kerke gedurende die sestiende eeu
}

\section{AD PONT}

\section{INLEIDENDE OPMERKINGS}

Wanneer die vraag gestel word na die invloed wat Calvyn uitgeoefen het op die samestelling van die ander kerkordes gedurende die sestiende eeu, soos die oorspronklike opdrag gelui het, ontstaan daar 'n paar probleme. Dit kan allereers verstaan word as 'n opdrag om Calvyn se persoonlike invloed en bydrae te probeer nagaan toe die Franse kerkorde in 1559 saamgestel is, by die ontwerp van die Skotse First Book of Discipline in 1560 en die Nederlandse kerkordenende beslissings tot en met 1564. So 'n ondersoek word nogal bemoeilik deur die feit dat die argivale materiaal oor hierdie sake nie in ons land bekombaar is nie. Verder is dit duidelik dat Calvyn se persoonlike bemoeiing met en invloed by die samestelling van die genoemde kerkordes betreklik klein was. Vir die grootste deel, miskien met die uitsondering van Frankryk, het Calvyn se invloed in die genoemde kerke, gedurende sy lewe en daarna, veral deurgewerk op grond van die Geneefse kerklike ordes van 1541 en 1561, deur sy geskrifte en deur sy opvattings wat veral deur sy volgelinge en studente uitgedra is (JT McNeill, 1967, p 244 asook FL Rutgers, 1899). Daarby kan die opmerking van Nijenhuis (W Nijenhuis, 1959, p 303) ook hier in berekening gebring word as hy stel dat: "... liturgie en kerkorde, ceremoniën en tucht, hoe belangrijk op zichzelf ook, voor Calvijn slechts een secundaire rol speelden in zijn oecumenische bemoeienissen".

Dit dui daarop dat vir die beantwoording van ons vraag daar buitendien nie 'n oorvloed van materiaal sal wees nie. Verder kan in

* Referaat gelewer voor die Kerkhistoriese Werkgemeenskap van Suid-Afrika, Stellenbosch, Januarie 1984. 
gedagte gehou word dat Spoelstra daarop wys dat die direkte invloed van Calvyn by die samestelling van die kerkordes van die Calvinisties-hervormde kerke nie so maklik bewysbaar is nie (B Spoelstra, 1982, p 232).

Dit wil dus voorkom dat dit miskien vrugbaarder sal wees om eerder ' $n$ poging aan te wend om vas te stel in hoeverre Calvyn se Skriftuurlike opvatting van die kerk, soos weergegee in sy geskrifte, weerklank gevind het in die Franse kerkorde van 1559, die Skotse van 1560 en die Nederlandse kerkorde van Emden van 1571. Dit moet toegegee word dat dit 'n verskraling of beperking is van die oorspronklike opdrag. Die hoop bestaan egter dat die weglating van 'n bespreking van Calvyn se invloed in die ecclesia Anglicana, die Hongaarse, Poolse en Duitse kerke nie ' $n$ te groot leemte sal laat nie.

\section{CALVYN EN DIE KERKLIKE ORDE}

In 1982 is 'n uitvoerige uiteensetting wat Spoelstra oor hierdie saak gegee het, gepubliseer (B Spoelstra, 1982, p 233-258). Omdat met die grootste deel van sy uiteensetting geen fout gevind kan word nie, is dit nie nodig geag om dit alles weer te herhaal nie. Miskien kan, ten oorvloede, slegs die volgende weer na vore gebring en beklemtoon word.

Calvyn, in navolging van Augustinus, onderskei die kerk in 'n sigbare en onsigbare kerk (Inst IV.1.7). In sy Geneefse Kategismus beskryf Calvyn die kerk as: "Die liggaam en gemeenskap van gelowiges wat God vir die ewige lewe bestem het" (Vraag 94. HW Simpson, 1981, p 20). Die uitverkorenes wat die kerk vorm (vgl Komm II Tim 2:19) is egter slegs aan God bekend en saam met hulle vorm die "huigelaars" (Inst IV.1.7) die sigbare kerk wat ons hoog moet ag en waarmee ons gemeenskap moet hou. Dié sigbare kerk is die organiese eenheid van alle gelowiges, wat alle belydende lidmate aansien as lidmate van die kerk en ook aanvaar en glo dat hierdie sigbare kerk die ware kerk is. Dié sigbare kerk is as ware of regte kerk aan twee notae ecclesiae herkenbaar, nl die suiwere prediking èn hoor van die Woord van God èn die bediening van die sakramente volgens die instelling van Christus (Inst IV.1.9). Altwee hierdie merktekens word deur die politia ecclesiae omraam (R Schwarz, 1961, Bd 1, S 202).

Wat die politia ecclesiae betref, is dit vir Calvyn van groot gewig. Immers Calvyn se vertrek uit Genève in 1538 het, vir 'n groot deel, 
saamgehang met sy eis dat daar 'n behoorlike kerklike orde in Genève moet wees. As hy na Genève terugkeer, word dit een van die voorwaardes dat ' $n$ behoorlike kerklike orde aanvaar sal word. Die disciplina is vir Calvyn 'n noodsaaklikheid, want hy is oortuig dat 'n kerk daarsonder ten gronde sal gaan (Inst IV.12.1).

Ten opsigte van die politia ecclesiae maak Calvyn hierdie belangrike uitspraak (Komm I Kor 11:2): "Want ons weet dat elke kerk die vryheid het om vir homself 'n kerklike orde (politiae formam) op te stel wat vir homself geskik en nuttig is, omdat die Here nie iets spesifiek voorgeskryf het nie." Die kerklike orde wat dus so geskep word, kom tot stand deur die instemming van almal in die kerk (Inst III.20.29). Dit hang saam, met inagneming van I Korintiërs 14:40, met die bevoegdheid wat alle kerke besit om sodanige wette en regulasies te maak as wat elkeen se omstandighede vereis ( $\mathrm{H}$ Beveridge en TF Torrance, 1958, Vol II, p 150).

Daarby stel Calvyn dat hy slegs menslike instellings goedkeur wat op die gesag van God gegrond is, uit die Skrif voortkom en dus geheel en al goddelik is (Inst IV.10.30). Daarmee bedoel Calvyn dat alle kerkordenende reëls moet voldoen aan die grondreël wat in I Korintiërs 14:40 gestel word: "Alles moet egter gepas en ordelik geskied." (Let op die vermaning in Inst IV.10.31.)

Dit is belangrik om daarop te let dat Calvyn die disciplina, wat by hom gewoonlik sowel die gubernatio as die censura morum omvat, nie tot die esse van die kerk reken nie, maar wel tot die bene esse (vgl Komm Matt 18:18). Die disciplina, so sien Calvyn dit, vloei voort uit die Woord en is noodsaaklik vir die bestaan, opbou en voortbestaan van die liggaam van die kerk (Inst IV.12.1), maar hy reken dit nié tot die notae ecclesiae nie (vgl die argument by BC Milner, 1970, p. 99 sq en ook by J Plomp, 1969, p 123-128). Calvyn stel mos dat die sigbare kerk 'n skool is waarin God ons opneem en waarin ons dwarsdeur ons aardse lewe bly. Die mens, in hierdie lewe, bly 'n verloste sondaar en kan, voor sy sterwe, nie die volmaaktheid bereik nie. Vandaar dat die censura morum so noodsaaklik vir die welwese van die kerk is.

As dit gestel word, moet weer beklemtoon word dat by Calvyn die essensiële van die kerk in die eenheid in die geloof in God geleë is en nié in die kerklike organisasie of instituut nie. Tereg wys Spoelstra daarop dat die Woordverkondiging en die diens van die dienaar van die Woord en wat dit impliseer, die kerk konstitueer. In sy voorlegging aan die Ryksdag van Spiers 1544 stel Calvyn in sy 
geskrif, Die Noodsaaklikheid om die Kerk te hervorm, dat in die kerk dit allereers daarom gaan dat die werklikheid dat Christus die enige hoof van die kerk is, gehandhaaf sal word. Dan sê hy: "As ek Christus sê, dan sluit ek daarby die leer van die evangelie, wat deur sy bloed beseël is, in. Ons teenstanders moet dus allereers, as hulle ons wil oortuig dat hulle die ware kerk is, anwys dat die ware leer aangaande God by hulle bestaan." Die kerk is primêr geloofsgemeenskap wat as 'n dinamiese begrip verstaan moet word, want waar die evangelie nie verkondig, gehoor en ontvang word nie, daar bestaan nie 'n kerk nie (Geloofsbelydenis van Genève 1536. AC Cochrane, 1966, p 125).

Interessant is dat by Calvyn die begrippe kerk, Woord en ampdiens baie naby aan mekaar lê, want die Woord of evangelie is vir Calvyn die verkondigde Woord, die viva vox evangelii, soos Luther dit formuleer. Soos die verkondigde Woord die kerk konstitueer, so konstitueer dit ook die amp-diens (vgl Komm I Tim 3:15) wat die primêre taak het om die Woord in die kerk te bedien ( $\mathrm{H}$ Beveridge en TF Torrance, 1958, Vol I, p 103).

So word dit in Calvyn se kerkordenende denke duidelik dat dit vir hom gaan om die beklemtoning van die feit dat Christus self die geloofsgemeenskap wat aan Hom behoort, regeer en dat dié geloofsverhouding die bepalende van die kerk is en moet wees en nie die politia ecclesiae of die disciplina van die georganiseerde kerk nie.

\section{DIE FRANSE, SKOTSE EN NEDERLANDSE KERKORDES EN CALVYN SE INVLOED BY HULLE SAMESTELLING}

Dit is, met die eerste oogopslag, wel duidelik dat die Franse, Skotse en Nederlandse kerkordes binne die dampkring van die Calvinistiese teologie en kerkordenende praktyk saamgestel is. As op meer besonderhede gelet word, is dit egter ook duidelik dat nie net Calvyn se invloed daar gegeld het nie. Miskien word dit die maklikste geillustreer deur die feit dat sowel in Frankryk (Confessio Gallicana, art 29) as in Skotland (Confessio Scotica, art 18) en in Nederland (Confessio Belgica, art 29) die disciplina as 'n derde merkteken van die ware kerk aangedui word.

Terwyl dié saak van nogal besondere gewig is, is dit seker die moeite werd om net 'n oomblik daarby stil te staan. Die beklemtoning van die handhawing van die dissipline-tug, die stryd vir die 
voortbestaan van die hervormde kerk met sy eie inhoud en struktuur, dwing die kerkleiers om vaste grenslyne te trek om so die kerk duidelik omlyn in die wêreld te stel. Dié noodsaak word die eerste deur Bucer in Straatsburg aangevoel waar hy op twee fronte, teen Rome en die Wederdopers moet afgrens. In sy afgrensing en sy duidelike trek van dié grense van die kerk word hy veral gesteun deur Oecolampadius van Basel en Wolfgang Capito, sy kollega te Straatsburg (PDL Avis, 1981, p 48-49). Bucer maak van die handhawing van die disciplina, dit wil sê die censura morum 'n merkteken van die kerk en juis deur dit te doen, wyk hy af van Calvyn se dinamiese kerkbegrip en begin hy 'n proses wat Avis (p 48) as "a progressive formalisation and clericalisation of the Church" aandui.

Hiervandaan word dié opvatting veral deur Beza verder gevoer wat nog met 'n geleentheid 'n skerp debat met Adrianus Saravia, die eertydse Leidse professor wat 'n kampvegter van die ecclesia Anglicana geword het, oor hierdie saak voer. (W Nijenhuis, 1980, p 220-221). Beza se opvattings wat die Engelse puriteine beïnloed, word veral in die puriteinse kringe verder gevoer en so kom hulle uit by die argument dat die kerklike orde in alles met die Skrif (moet) ooreenkom om so die kerkorde op dieselfde vlak as die belydenisskrif te stel. Dit beteken dan dat die kerklike lidmaatskap voorwaarde word vir die geloofsverbondenheid met Christus, die enige hoof van die kerk. Daarmee is Calvyn se argument presies omgedop. Tereg stel Wendel in verband met Calvyn se opvatting ( $F$ Wendel, 1978, p 297): "It is not, therefore, by the quality of its members, which should give occasion for a subjective judgment, but by the presence of the means of grace instituted by Christ, that the Church is constituted and can be objectively judged."

Dit kan gestel word dat by Bucer en in die kerkordes onder bespreking die opname van die dissipline as 'n merkteken van die kerk nié hierdie laat-16de-eeuse en 17de-eeuse skeeftrekking bedoel het nie. Maar dit staan wel vas dat hiermee 'n invalspoort geskep is wat Calvyn juis wou vermy het. So het dit gebeur dat 'n ekklesiologiese denkfout, wat veral in die Anabaptistiese kringe gepropageer is, in die Calvinistiese kerke ingesluit het. In ons dae het dit nog tot veel groter dwaashede aanleiding gegee.

Met hierdie opmerking word dus net aangetoon dat in die kerkordes onder bespreking Calvyn se invloed en opvattings nie al te vanselfsprekend aanvaar moet word nie. 


\subsection{Die Franse Kerkorde van 1559}

As gevra word na Calvyn se invloed op die Franse Discipline Ecclésiastique van 1559, dan kan allereers daarop gewys word dat Calvyn 'n besonder noue band met die Franse kerk gehad het. Calvyn en Genève was in meer as een opsig 'n voedingsbron vir die Franse kerk.

Die Franse kerkorde, 'n aanhangsel van die Confessio Gallicana 1559 , en 'n verwerking, na die Geneefse model, van 'n kerklike orde wat in 1557 deur die predikante van Poitiers opgestel is, toon duidelike spore van Calvyn se invloed (vgl AD Pont, 1981, p 48 en ook $\mathrm{H}$ Jahr, 1965, p 19-28). Saamgelees met die Confessio Gallicana en die Geneefse kerkorde van 1541 is Calvyn se invloed duidelik merkbaar. Dit kan ook nie anders nie want Calvyn, Beza en Viret was die oorspronklike opstellers van die Confessio terwyl Calvyn se leerlinge in die Franse sinode die finale teksversorging waargeneem het (A Cochrane, 1966, p 138).

Byna vanselfsprekend, kan gesê word, word Jesus Christus as enige hoof van die kerk bely (CG, art 30) met wie die liggaam, die kerk verbind is deur die genadegawe van die geloof (CG, art 25). Die regering gubernatio, van die kerk is geleë in die Woordverkondiging en die daarmee gepaardgaande opbou van die liggaam van Christus (CG art 27). Ter wille van die Woordverkondiging is die diens-amp ingestel en daar word in drie dienste onderskei nl die predikante, die ouderlinge en die diakens. Rondom die diens-amp word die bekende, Calvinistiese voorwaardes ten opsigte van eksaminering, toelating, roeping en bevestiging uiteengesit (JL Ainslie, 1940, p 139-199). Opmerklik is dat die diaken rondom die Woordverkondiging 'n hulpdiens kan verrig wat as sodanig nog deur Calvyn nog deur die ander Calvinistiese ordes aangedui word nie (DE, art 24).

Die diens-amp van die doctor word nie genoem nie, waarskynlik omdat Genève op hierdie stadium die vanselfsprekende teologiese opleidingsentrum vir die Franse predikante is.

Interessant is dat in hierdie kerkorde daar nie sprake is van 'n aparte vergadering van predikante soos dit in Genève gebruiklik was nie (vgl Geneefse OE, art 20). Miskien vanweë die feit dat in Frankryk die kerkraadsvergadering nie deur owerheidspersone bygewoon is en die ouderlinge ook nie uit owerheidspersone gekies moes word nie (OE, art 48-50), is geoordeel dat die kerkraad die regeerliggaam van die gemeente is (vgl B Spoelstra, 1982, p 252). Dit 
het wel meegebring dat die enigsins unieke posisie wat die Geneefse predikante gehad het, hier anders gesien is. Opvallend is dat hier nié 'n gelykheidsbeginsel ten opsigte van die ampte gestel word nie maar alleen ten opsigte van die predikante onderling (CG, art 30). Oor die figuur van die superintendent wat hier voorkom (CG, art 32) oordeel Ainslie (p 95-97) dat hier nié van 'n hiërargiese figuur sprake is nie.

Anders as by Genève, waar die noodsaak nie bestaan het nie, word hier ruimte geskep vir meerdere vergaderings (CG, art 32 en $D E$, art 2-5 en 39) en word deur die Franse voorbeeld die regering van die nasionale kerk deur middel van meerdere vergaderings in die Calvinistiese kerkordenende denke ingedra (vgl J Plomp, 1971, p 94). Terloops mag net gestel word dat hier nie aandag gegee word aan die problematiek van die verhouding plaaslike kerk-gemeente en nasionale kerk nie. Dit sou meebring dat daar aandag gegee sou moes word aan 'n reeks van vrae wat in die 16de eeu nie eksplisiet aan die orde was nie.

Die doel van die diens-amp en die inrigting van die kerk word hier gesien om die geloof by die lidmate te wek en op te bou, om die heiliging van die gemeenskap te bevorder deur die eenheid in die geloof en lewenstyl na te streef (CG, art 27 en 29). Juis vir dié rede is die censura morum noodsaaklik om die karakter van die kerk as liggaam van Christus te bewaar. Interessant is dat in hierdie verband ' $n$ sondelys voorkom (DE, art 28), maar nié 'n lys domineesondes nie.

Vanweë die feit dat die hervormde kerk in Frankryk nié deur die owerheid erken is nie, word hier geen rol aan die owerheid in die kerklike bedeling gegee nie.

Wat die hoofmomente van die kerklike orde betref, kan gesê word dat dit 'n tipiese Calvinistiese kerklike orde is, hoewel nie alles stiptelik volgens Calvyn se insigte geformuleer is nie.

\subsection{Die Skotse "Book of Discipline" van 1560}

Die Skotse Geloofsbelydenis en die Skotse kerkorde, die Book of Discipline, is beide in 1560 deur die Skotse Parlement aanvaar. Beide was in hoofsaak die werk van 'n kommissie van Skotse, Calvinistiese teoloë onder leiding van John Knox (JHS Burleigh, 1961, p 164). Hier ontstaan, net soos in Genève, 'n owerheidsreëling wat aan die kerk 'n bepaalde orde gee sonder dat ' $n$ kerklike vergadering die aanvoor- 
werk doen. In 'n sekere sin was dit verstaanbaar, want op daardie tydstip was daar nog nie werklik hervormde, Calvinistiese gemeentes nie.

As op die twee belangrike stukke gelet word, dan word die tipiese Calvinistiese twee-eenheid van belydenisskrif en kerkorde ook hier gevind en is dit duidelik dat die kerkorde ' $n$ aanhangsel van die doctrina ten opsigte van kerk is, soos dit in art 16, 18 en 20 in die belydenisskrif gegee word.

Waar die Geneefse orde uit 173 artikels bestaan wat in hoofsaak handel oor die diens-ampte, die seremonies (waaronder die huweliksreg met 52 artikels) en die dissipline-tug en die Franse kerkorde bestaan uit 40 artikels wat handel oor die vergaderings, die diensampte, die dissipline-tug, die huwelik en die gesag van die meerdere vergadering, is die Skotse kerkorde verdeel in 9 hoofstukke. Hier word agtereenvolgens gehandel oor die verkondiging, die sakramente, die afskaffing van die afgode-diens, die diens-amp van die dienaar van die Woord, die stoflike versorging van die kerk, die kerklike dissipline, die verkiesing van ouderlinge en diakens en ten slotte oor die regering van die kerk (D Laing (ed), 1848, p 182-260).

By die deurlees van die Skotse kerkorde word dit duidelik dat in die 16de-eeuse Calvinisme daar nie so iets soos 'n standaard-kerkorde bestaan het nie. Elke kerk het self, na die eise van sy omstandighede, 'n eie kerkorde opgestel.

In die Book of Discipline het ons, in sekere sin, nog nie met 'n werklike kerkorde te make nie. Dit is 'n voorlegging aan die Skotse Parlement wat net so deur dié owerheidsliggaam as ' $n$ owerheidsreëling aanvaar is. Hier word dus wel grondreëls vir die ordelike bestaan van die kerk neergelê. Die aanhef vertel hierdie verhaal: "Most humbly requiring your Honours, that as you look for participation with Christ Jesus, that neither you admit anything which God's plain Word shall not approve, neither yet that you should reject such ordinances as equity, justice and God's Word do specify: For as we will not bind your wisdom to our judgments farther than we be able to prove the same by God's plain Scripture; so must we humbly crave of you ... that you repudiate nothing for pleasure nor affection of men, which you be not able to improve by God's written and revealed Word."

Dit is, sover vasgestel kon word, net hiér en in die Wezelse Artikels, art 11, waar in die Calvinistiese kerkordes die bronne van die kerklike reg aangedui word. 
Interessant is dat die eise van equity en justice hier genoem word.

Dit dui tog daarop dat die Skotse Parlement nie net gevra word om 'n kerklike orde te aanvaar nie, maar ook 'n ordereëling vir die Christelike Commonwealth (JHS Burleigh, 1961, p 165). Dit sou, terloops, tog die moeite moet loon om 'n ondersoek in te stel na die drakrag en strekking van die Roomse begrip van die corpus christianum, die Calvinistiese respublica christiana en die Skots-Calvinistiese begrip commonwealth en dan ook hóe die kerk daar inpas. Dit is duidelik dat hierdie begrippe ' $n$ ander dinkwêreld aandui as ons godsdienstig-neutrale staat waarin 'n pluriformiteit van kerklike organisasies bestaan.

As op die inhoud van die Book of Discipline gelet word, word dit duidelik dat dit eintlik 'n voorafgaande kerklike reëling is. Die hoofklem lê op die verkondiging van die evangelie, die bediening van die sakramente en die opvoeding van die kerkvolk. Hoewel daar van die plaaslike gemeente gepraat word, is dit nié so spesifiek soos die gewone Calvinistiese kerkordes nie. Die meerdere vergaderng word ook eerder gesuggereer as duidelik gestel.

Die noodsaaklikheid om die afgodediens uit te roei, word hier stilswyend aan die owerheid opgedra en hang saam met Knox se eie siening van die verhouding God-volk en koning-volk (vgl D Shaw, 1975, p 63-72). Hier word dit duidelik dat Knox en sy medestanders geen kontinuïteit met die Roomse verlede wil hê nie. Hier word baie skerp teen Rome afgegrens en gestel dat die ware kerk alleen herstel kan word as die Skriftuurlike suiwerheid in leer, godsdiensoefening en dissipline weer herstel is.

Wat die diens-amp van die dienaar van die Woord betref, is die kerkorde weer op die Calvinistiese lyn. Die klem op 'n deeglike opleiding vir die predikant is ' $n$ tipiese moment wat van Calvyn oorgeërf is.

Twee merkwaardighede kom by die ampte na vore. Enersyds word die hulpdiens van die Reader ingestel wat nie alleen in die godsdiensoefening kan voorgaan nie, maar ook mettergaan die sakramente sal mag bedien. Hier word 'n hulpdiens geskep wat sonder beroep-verkiesing of -bevestiging meer bevoegdhede besit as die min of meer vergelykbare Nederlandse figuur van die voorleser of die sieketrooster.

Saam met die Reader word melding gemaak van vaste superintendente wat veral opsig oor die predikante en hulle prediking het. Die Skotse ouderling het hier wel 'n opsigtaak ten opsigte van die le- 
wenswandel van die predikant, maar nié 'n uitgesproke opdrag ten opsigte van die prediking nie.

In 1560 is die situasie van die Skotse Kerk egter sodanig dat bepaalde eiesoortige reëlings noodsaaklik is. Die Second Book of Discipline van 1577, wat hoofsaaklik die werk van Melville is, kom baie sterker terug na die presiese Calvinistiese ordereëlings in hierdie verband. Tog lê 1560 se orde-reëling, al is dit dan nie so spesifiek nie, die basiese presbiteriale organisasie van die kerk vas. Tog kan gesê word dat dit eers die Second Book of Discipline is wat die presiese Calvinistiese orde vir die Skotse Kerk na vore bring.

In 1560 kom daar meer nie-Calvinistiese momente na vore. Een daarvan is die instelling van die profesie met ' $n$ beroep op I Korintiërs 14:29. Om die kennis, die verstaan van die Skrif en om die kwaliteit van die prediking te bevorder word die profesie, na die voorbeeld van Zürich, ingestel. Soos bekend was Calvyn nie besonder op dié gebruik gesteld nie (AD Pont, 1981, p 72). Die gebruik word egter nie in 1577 bestendig nie.

Opvallend is die nadruklike klem wat op die skool en die opvoeding gelê word. Dit hang weer saam met Knox se verklaarde opvatting dat die hervorming van die kerk alleen moontlik is as dit gepaard gaan met onderwys van die jeug en die opvoeding van die kerkvolk. Hierin loop die Skotse orde veral met die Nederlandse ordes op een lyn waar vanuit die leer van die verbond die kinders van die gelowiges besondere aandag ontvang (vgl Calvyn se skrywe aan Knox van 8.11.1559 by R Schwarz, Bd 3, S 1032-1034).

Die kerklike censura morum word duidelik omskrywe en veral as taak aan die ouderling opgedra. Opvallend is dat die Geneefse lys van domineesondes hier ook genoem word.

Wat die inrigting van die godsdiensoefening betref, word geen aanwysings gegee nie omdat die Book of Common Order van die Engelssprekende gemeente van Genève in gebruik was (D Laing, 1848, p 210).

Oor die algemeen kan gestel word dat die Book of Discipline van 1560 nie baie sterk aan Calvyn herinner nie. Miskien ook vanweë die feit dat dit nog nie werklik 'n kerkorde, in die gewone sin van die woord is nie, het ander invloede en Knox se eie siening hier sterker deurgewerk. Die Second Book of Discipline van 1577 stel egter die Calvinistiese kerklike orde vir Skotland vas. 


\subsection{Die Nederlandse Kerkorde van Emden}

As die Nederlandse situasie besien word en na Calvyn se invloed daar gevra word, dan is dié saak ook nie vanselfsprekend nie. Rutgers (FL Rutgers, 1899, p 5) het aangetoon dat Calvyn se invloed in die Nederlande nie onbeduidend was nie. Nie alleen deur middel van medestanders nie, maar ook deur oud-studente waaronder daar manne van die kaliber van Petrus Datheen, Van der Heyden, De Brès en Taffinus was, het Calvyn se invloed deurgewerk. Daarby het sy geskrifte ook 'n belangrike rol gespeel.

'n Verdere middel waardeur Calvyn se invloed verbrei is, is deur die feit dat die Franse Kerk aanvanklik in die suidelike Nederlande die oorheersende invloed gehad het (vgl J Lindeboom, 1946, p 74-78).

Verder kan op die Calvinistiese invloede gewys word wat deur middel van die verskillende vlugtelinggemeentes op die kerk in Nederland self deurgewerk het. Hier kan veral gedink word aan die "precieze Calvinisme" van die Paltz (J Lindeboom, 1946, p 84) wat veral deur middel van Datheen en sy werk so ' $\mathrm{n}$ vormende invloed op die Nederlandse Kerk in sy wordingsjare gehad het.

As die invloed van Calvyn op die kerklike orde nagegaan word, dan moet allereers gewys word op die beginjare 1563-1566. In daardie tyd leef die kerke onder die kruis, kerkordelik gesproke, met die Franse kerkorde as basis (AD Pont, 1981, p 55-57). Hoe sterk die Frans-Calvinistiese invloed was, blyk daaruit dat die Nederlandse Geloofsbelydenis wat in 1561 deur De Brès opgestel is, die Confessio Gallicana as voorbeeld en basis het. Dié belydenis wat in 1566, na 'n revisie van art 36 deur die Sinode van Antwerpen, in Genève goedgekeur is, is nie alleen in 1568 by Wezel as belydenisskrif van die kerk aanvaar nie maar ook weer in 1571 te Emden. Verder word die konfessionele inhoud van die kerk vanaf 1568 medebepaal deur die reëling dat sowel die Heidelbergse as die Geneefse Kategismus as leerboek vir die jeug gebruik sal word. Hoewel Calvyn self al in 1564 oorlede is, is dit tog duidelik, in die breë gesien, dat sy kerkordelike denke die gang van sake in Nederland bepaal het.

Die sterk Calvinistiese inhoud van die Nederlandse Kerk word enigermate getemper by die Convent van Wezel 1568 waar 'n voorbereidende kerkorde opgestel is. Die Wezelse Artikels verteenwoordig 'n dubbele kerkregtelike tradisie.

Enersyds is daar die kerkordelike voorbeeld van die Londense vlugtelinggemeente en andersyds die Geneefs-Frans-Waalse tradi- 
sie. Dankbaar (WF Dankbaar, 1956, p 17-18) wys daarop dat die Londense Christlicke Ordonnanciën veral op die kerkordelike voorbeeld van Zürich gebaseer is. Dit wil nie sê dat daar geen Calvinistiese elemente in die kerkorde is nie, maar wel dat dit nie die bepalende is nie. Dankbaar wys ook daarop dat Micron en Joh à Lasco, wat vir die Londense orde verantwoordelik was, nie die Geneefse kerkorde kon geraadpleeg het nie omdat die 1541 Ordonnances Ecclésiastique nooit, in daardie tyd, in druk verskyn het nie.

Aan die ander kant moet ook weer in gedagte gehou word dat die Londense Ordonnanciën hoofsaaklik reëlings ten opsigte van die godsdiensoefening tref en daarom was die invloed daarvan te Wezel tog beperk.

Die Wezelse Artikels begin, na die Franse voorbeeld, met die vergaderings wat veral daar is vir die gemeenskaplike handhawing van die leer, die seremonies en die tug. Die "zuivere belijdenis der heilige waarheid" (art 2) word beklemtoon en word dit duidelik dat 'n goed georganiseerde, vaste kerklike organisasie die doelwit van die kerkorde is. Hier word reeds drie meerdere vergaderings genoem, nl die klassis, die provinsiale sinode en die algemene sinode.

Wat die ampte betref word die bekende vier genoem en die omskrywing daarvan lê volkome in lyn met die gebruiklike Calvinistiese eise en formulerings in hierdie verband.

Hier word ook Collegiën der propheten (art 26-33) na die voorbeeld van die Londense gebruik, in die vooruitsig gestel. Dié reëling word nié by Emden oorgeneem nie en dit verdwyn dan, vir sover dit ooit in die Nederlandse kerklike lewe werklik gefunksioneer het.

Die reëlings ten opsigte van die kerklike dissipline is grotendeels 'n verwerking van die Geneefse bepalings en die lys van domineesondes is grotendeels van Genève afkomstig.

Hierdie kerkorde het nooit in die Nederlandse Kerk gefunksioneer nie, want die eerste nasionale sinode van die Nederlandse Kerk wat in 1571 te Emden gehou word, stel 'n eie kerklike orde op. Hoewel dit moontlik is dat die Wezelse Artikels te Emden geraadpleeg is, het dit daar min invloed uitgeoefen.

Die kerkorde wat in $\mathbf{1 5 7 1}$ by die eerste nasionale sinode van die Nederlandse Kerk opgestel is, vorm 'n nuwe begin. By Emden word 'n kerklike orde opgestel wat die grondpatroon word vir alle verdere kerkordes wat in die Nederlandse Kerk saamgestel is. In 'n sekere sin kan gesê word dat al die kerkordes, tot en met dié van Dordrecht 
1619 , niks meer is as uitbreidings en verbetering van die kerkorde van Emden nie.

As op die inhoud van die Emdense orde gelet word, is dit dadelik duidelik dat die Calvinistiese kerklike denke hier triomfeer. Emden sluit dan ook nou by sowel die Franse tradisie as die tradisie van die kruisgemeentes aan (art 2). ' $n$ Interessante moment is dat hierdie kerkorde begin met ' $n$ anti-hiërargiese klousule (art 1) en afsluit met 'n anti-independistiese artikel (art 53). Binne hierdie raamwerk word ' $n$ kerklike orde met ' $n$ vaste hand gebou wat enersyds teen Rome en andersyds teen die Anabaptiste gerig is. Daarom word nie net die inhoud van die kerk nie maar ook die grense van die kerk presies aangedui.

Interessant is die stelling wat Plomp (J Plomp, 1971, $p$ 96) na vore bring, $\mathrm{nl}$ dat die anti-hiërargiese artikel nie ' $\mathrm{n}$ bepaalde voorrang van die dienaar van die Woord ten opsigte van die ampte van ouderling en diaken uitskakel nie. By Emden waar gestel word dat die predikant sy dienswerk lewenslank moet vervul, dat hy alleen na behoorlike studie en ' $n$ suiwer lewenswandel tot die amp toegelaat kan word, word verder ook gereël dat op die meerdere vergaderings daar steeds 'n oorwig van predikante sal wees. So word die gelykheidsbeginsel ten opsigte van die ampte onderling nie baie sterk gehandhaaf nie.

Dit is nogal opvallend omdat Calvyn in beginsel nie geneë was om enige amp ' $n$ soort voorrang in die regering van die kerk te gee nie, (Inst IV.4.4) en hy het veral stelling ingeneem teen die gedagte dat die predikant 'n soort "gesagsfiguur" sou wees (Komm Matt 20:25 en ook Komm I Pet 5:1).

Aan die ander kant moet ook weer daarop gelet word dat die kerkordenende uitgangspunt dat Jesus Christus self die enige hoof van sy kerk is, ook by Emden gegeld het. Dit is juis die sterkste bolwerk teen enige bewuste of onbewuste hiërargie-vorming. Daarby blyk uit die struktuur van die kerklike vergaderings dat die gesamentlike besluitneming op die voorgrond staan en dit is ' $n$ tweede bolwerk teen 'n hiërargie-vorming.

Dit is duidelik, ook as op die reëlings ten opsigte van die dissipline gelet word, dat hier heeltemal in die Calvinistiese kerkordelike tradisie gewerk word. Emden is seker een van die duidelikste voorbeelde hoe sterk die Calvinistiese invloed in die Nederlandse Kerk gegeld het (AD Pont, 1981, p 95). 


\section{ENKELE SLOTOPMERKINGS}

Calvyn beklemtoon in sy beskrywing van die kerk, wat hy as die moeder van die gelowiges tipeer, dat die verkondiging van die evangelie van Jesus Christus, wat Luther genoem het "die vrolike boodskap van die regverdiging", die primêre taak van die kerk is. Deur daardie verkondiging word die kerk, die gemeenskap van die heiliges wat deur die geloof met Christus, die hoof van sy liggaam verbind is, in aansyn geroep. So gesien is die kerk by Calvyn 'n middel tot ' $n$ doel, 'n dinamiese geloofsgemeenskap wat in die wêreld, tot eer van God, op weg is en diensbaar is aan die koninkryk van God (vgl BC Milner, 1970, p 194-195).

Betreklik gou egter het die hervormde kerk wat moes afgrens teen Rome en sektariese groeperinge en óók teenoor die owerheid al meer 'n vaste, omlynde, statiese en jurisdies-hanteerbare organisasie geword. Miskien kon dit nie anders nie. Tog is dit so dat die kerk wat aanvanklik deur Calvyn as ' $n$ middel tot ' $n$ doel gesien is geleidelik 'n doel in homself geword het.

Die kerkordes onder bespreking toon, waar die klem lê op die prediking, waar die amp omskryf word as 'n dienswerk, waar die dissipline gesien word as 'n leerskool tot heiligmaking baie duidelik die invloed van Calvyn se dinamiese kerkopvatting. Maar na 1564 as Beza geleidelik al meer na vore kom, begin die statiese kerkbegrip na vore kom. Dit blyk miskien ook daaruit dat Beza dit goedgedink het om Saravia tereg te wys omdat hy die saak van heidensending as 'n taak van die kerk sien (PDL Avis, 1981, p 175).

Dit is duidelik uit die geskiedenis dat in die sewentiende eeu die dinamiese, Skriftuurlike kerkbegrip van Calvyn vir 'n baie groot deel oorwoeker word deur die staties-juridiese kerkbegrip wat geleidelik na vore gekom het. Dieselfde woorde was nog daar, die grondlyne wat Calvyn getrek het, is nog steeds gehandhaaf. Tog het die geheel geleidelik verstar. Die prediking was nog regte prediking in dié sin dat dit konfessioneel onbesproke was, maar dit was nie meer die viva vox evangelii nie. Vandaar die reaksie van die Nadere Reformasie, vandaar die onvermoë van die kerke om in die 18de en 19de eeue die opkomende Aufklärung en Rasionalisme werklik vanuit die Woord van God die hoof te bied.

Boekelys

Ainslie, JL 1940. The Doctrines of Ministerial Order in the Reformed Churches of the 16th and 17th Centuries, Edinburgh. 
Avis, PDL 1981. The Church in the Theology of the Reformers, London.

Beveridge, $\mathrm{H}$ and Torrance, TF 1958. Tracts and Treatises on the Doctrines and Worship of the Church by John Calvin, 3 Vols. Edinburgh.

Burleigh, JHS 1961. A Church History of Scotland, London.

Cochrane, A 1966. Reformed Confessions of the 16th Century, London.

Dankbaar, WF (red.) 1956. Martin Micron: De Christlicke Ordonnanciën der Nederlantscher Ghemeinten te Londen 1554, Den Haag.

Jahr, H 1965. Studien zur Ueberlieferungsgeschichte der Confession de foi von 1559, Neukirchen.

Laing, D (ed.) 1848. The Works of John Knox, Edinburgh.

Lindeboom, J 1946. De Confessioneele Ontwikkeling der Reformatie in de Nederlanden, Den Haag.

McNeill, JT 1967. The History and Character of Calvinism, New York.

Milner, BC 1970. Calvin's Doctrine of the Church, Leiden.

Nijenhuis, W 1959. Calvinus Oecumenicus, Den Haag.

Nijenhuis, W 1980. Adrianus Saravia. Leiden.

Plomp, J 1969. De Kerkelijke Tucht bij Calvijn, Kampen.

Plomp, J 1971. De Kerkorde van Emden, in D Nauta et al (red.), De Synode van Emden Oktober 1571, Kampen.

Pont, AD 1981. Die Historiese Agtergronde van ons Kerklike Reg, Pretoria.

Rutgers, FL 1899. Calvijns Invloed op de Reformatie in de Nederlanden voor zooveel die door hemselven is uitgeoefend, Leiden.

Spoelstra, B 1982. Calvin's Canon Law and influence on churches in South Africa, in Calvinus Reformator, Potchefstroom.

Simpson, HW 1981. Calvyn se Kategismus, Potchefstroom.

Schwarz, R 1961. Johannes Calvins Lebenswerk in seinem Briefen, 3 Bande, Neukirchen.

Shaw, D 1975. John Knox and Mary, Queen of Scots, in D Shaw (ed.), John Knox, Edinburgh.

Wendel, F 1978. Calvin. The Origins and Development of his Religious Thought, London. 